\title{
Commentary: Mediality, mediatization and sociolinguistic change
}

\author{
Spitzmüller, Jürgen
}

Posted at the Zurich Open Repository and Archive, University of Zurich ZORA URL: https://doi.org/10.5167/uzh-98728

Book Section

Published Version

Originally published at:

Spitzmüller, Jürgen (2014). Commentary: Mediality, mediatization and sociolinguistic change. In: Androutsopoulos, Jannis. Mediatization and Sociolinguistic Change. Berlin and Boston: De Gruyter, 361-367. 


\section{Commentary: Mediality, mediatization and sociolinguistic change}

The three chapters in this section deal with aspects of change on the level of genres. Although all three chapters (at least mainly) focus on genres of news reporting, they do so in quite different ways. Ulrich Schmitz' chapter describes some rather fundamental changes in the way texts are composed and structured (primarily) by example of newspaper and online news genres. He suggests that textual genres in general, and in particular news reporting genres (and consequently the consumption of news), are subject to grave transformation processes in the wake of media evolution. Martin Luginbühl looks at the changes of functional interrelations between sub-genres of the "super-genre" TV news. Rather than general media change, he is interested in structural change within this particular "super-genre", primarily as far as selection, linking and balancing of functional parts within news shows is concerned (in Saussurean terms, we could say he is concerned with the changing "values" of [sub-]genres within a "supergenre"). Lauren Squires and Josh Iorio, finally, focus on how a genre is entextualized within, and thus inter-generically linked to, another genre and how such entextualization changes over time and with the growing social establishment of the embedded genre. Rather than with the question what "makes" up a (super-) genre, these two authors therefore deal with the question of how different genres relate and link to each other, and how these links are subject to sociolinguistic change.

The differences, however, do not only concern the scope of the analysis. When reading these three chapters, asking how they relate to this section's theme "change in media language and media discourse" as well as towards each other, I was struck by the conceptual differences more than by what connects the chapters. In my comment, I will thus start with these conceptual differences. This is certainly not to say that the three chapters do not have any connections. On the contrary. All authors obviously share the fundamental idea that sociolinguistic change manifests itself in change of communicative patterns and routines. Therefore, they regard this level of routines and patterns - the generic level - as a key to the understanding of sociolinguistic change, as a strong link between social actors and the media. The different ways of depicting this connection in the three chapters, however, strikes me as most interesting, since it brings to the fore some issues which, even if they are well-known and long-discussed, still seem to be dissensual and crucial in socio and media linguistics. 
In a second step, I will (fully aware that this complicates the picture even more) propose yet another perspective, which is not really missing from these chapters, but is perhaps not as clearly developed as it could be. I will propose, as a complement to media and mediatization, the concept of mediality and try to show with regard to the chapters focused here, why I think this complement is useful for the analysis of mediatization and sociolinguistic change.

\section{1 'Media' - 'mediality' - 'mediatization'}

It is a truism that medium and media are notoriously weak and ambiguous, but also heatedly discussed concepts in media studies (see Androutsopoulos, in this volume). Due to its "complicated etymology" ("verwickelte Begriffsgeschichte"; Mersch 2009: 12), medium may well mean quite different things in different texts, depending on the disciplinary or scholarly tradition these texts are located in. This also becomes apparent in the three chapters. Whereas Schmitz primarily understands media as technical tools that provide specific possibilities for communication (which is a quite common notion especially in German media linguistics; see Habscheid 2000 for a survey), Luginbühl as well as Squires and Iorio regard the media primarily as social institutions consisting of more or less powerful groups of actors (such as journalists). This is a concept originating in cultural studies (cf. Hepp, in this volume), which is becoming increasingly popular in linguistics (cf. Androutsopoulos, in this volume; Johnson and Ensslin 2007).

As far as language and sociolinguistic change are concerned, these different notions result in fundamentally different assumptions about the causes of change. From Schmitz' point of view, media themselves 'cause' language change (or change of language use, for that matter) due to the changing forms of communication they allow for ("the media intensify, accelerate and differentiate language use"). Luginbühl as well as Squires and Iorio, on the other hand, highlight that media are driven by social agents, people who use media and make sense by means of media. In this view, it is not so much the language that is controlled by the media. Rather, the media (and through them, language) are controlled by social actors and institutions. Thus, these chapters (explicitly at least Luginbühl's, likewise Androutsopoulos, in this volume) reject "the idea of technological changes as driving force behind genre change” (Luginbühl, in this volume), or the "technological determinism", as this idea is somewhat disparagingly termed (Androutsopoulos 2006: 421; Luginbühl, in this volume). Instead, they put forward the idea that strong institutions ("journalistic communities" which "may be small, but their social impact can be huge", as Luginbühl has it) drive forward media, genre and language change. 
Furthermore, the notion of media as tools that 'enable' or 'ease' communication is connected with the idea that media should provide, and media/language change tends towards, "maximal communicative efficiency" (Schmitz, in this volume; also cf. Schmitz' basic concept of "semiotic economy"). A 'good tool' is an 'efficient tool', after all. Moreover, this idea is perfectly in line with the transportational model of communication/mediation which often underlies conceptions of media as tools (cf. Schneider 2006). The notion of media as institutions, on the other hand, seems to be connected with the idea that media serve the interests and express the ideology of the institutional actors, an idea which still bears the media- and socially critical heritage from the context it was developed in, although the critical impetus is not made very explicit in these chapters. In any case, both concepts have many implications, which become manifest in the way the respective chapters depict media, mediatization and media/language change, in other words: each of these concepts highlights and hides different aspects of media.

In addition to the discussed concepts, however, Squires and Iorio as well as Luginbühl scratch a third notion of medium when they draw on Gershon's (2010: 389) concept of "media ideology" (Squires and Iorio) and on Barnhurst's and Nerone's (2001: 3) idea of "medial self-imagination" (Luginbühl), respectively. Both notions are in line with what Hepp (in this volume) calls the "social-constructivist tradition" of mediatization research. They put into focus a concept which indeed should be considered next to the central concepts discussed in this volume (media and mediatization), namely mediality. Mediality is a term which has become increasingly popular in German media theory (cf. Scheider 2008). It transfers the well-known distinction between text and textuality to the level of media, in the sense that it focuses on the (perceived) conditions of something which is considered 'a medium' just as textuality focuses on the "textual conditions", i. e. the perceived conditions of something which is considered 'a text' (see McGann 1991). Mediality, thus, is an interpretive phenomenon which, as it were, is to be found in they eyes of the beholders, i. e. which puts the recipients of mediated communication to the fore. Mediality is connected to mediality expectations, what recipients think 'is' a medium, what recipients think a particular medium can 'accomplish' (the "function a genre is thought to fulfil within a community"; Luginbühl, in this volume), what people think a form of mediation 'tells' about the message or the messenger. It also is connected to mediality perceptions, i.e. the way in which, and the degree to which, recipients perceive something as being 'mediated' (what Bolter and Grusin 1999: 19 call the "immediacy-hypermediacy-continuum"). Furthermore, mediality is connected to mediality ascriptions, the values, features, abilities and limitations social actors ascribe to something they perceive as being a particular 'medium' (these ascriptions are, as it were, what Gershon calls “media ideologies”). 
Medium, mediality and mediatization are closely interconnected, but they describe different things nonetheless. A 'medium', from an interpretive point of view, is something to which 'mediality' is ascribed, and the mediality (i.e. the expectations, perceptions and ascriptions of particular social actors) determines whether and how a 'medium' is delimitated from and/or connected with other 'media'. From this perspective, it is well possible that technology plays the main role and indeed 'determines' media use, if technology is perceived as the main factor by the media recipients (i. e. is discursively central). However, it might as well be possible that institutions play the main role and 'determine' media use, if institutions (or specific groups of actors) are perceived as the main factor by the media recipients.

If we look at media history (and the history of media studies, for that matter), we can clearly observe how media are conceived differently in different times. The crucial question is, why this is the case. One possible answer is: because we observe (discursive) changes in mediality (cf. Spitzmüller 2013: 29-58 for an elaboration of this argument). As far as mediatization is concerned, it can be argued that mediatization - if conceived as "the proliferation of media communication in all areas of social life and the central role of media in socio-cultural change" (Androutsopoulos, in this volume) - relies on mediality, the degree to which and the way how this "proliferation of media communication" is actually perceived and evaluated by specific social actors. Drawing on Agha's (2005) most seminal concept, we can also say that mediality describes the way in which media and the process of mediatization are culturally 'enregistered' (see Section V) and thus socially or discursively 'visible'. In other words: sociolinguistic change may entail a change of perceived media conditions - a change of mediality.

\section{Cui bono?}

What do we gain with yet another level of analysis? In the following, I intend to exemplify the usefulness of the proposed concept with regard to the three chapters in question. Nota bene, my comments here are to be read as complementary thoughts, which do not aim to challenge the argumentation of the chapters. On the contrary. Just as the three chapters complement each other through their different perspectives on the subject (and their different conception of the subject), my comments suggest how a more systematic interpretive perspective could broaden the picture (just as the instrumental and institutional notions of media described above complement and broaden the picture drawn by an interpretive analysis). Since this is a comment and not a full chapter of its own, I crave the reader's indulgence for the highly indicative character of the following. 
Schmitz highlights the grand trends in his chapter: the trend towards 'efficiency' or 'economy', the trend towards 'fragmentation', the trend "from fulltext reading to selective reading" and so on. As always when such long lines are drawn, we are obliged to ask: can things really be described in such general terms? There is no doubt that the structure of newspapers has changed significantly; there is plenty of evidence for this (see Barnhurst and Nerone 2001; for German newspapers see e.g. Bucher 1998). Also, it is well likely that the internet has brought new forms of text into attention. However, from an interpretive point of view, the stress is on attention. As historical sociolinguistics begins to reveal, the 'typical' forms of text we used to compare the 'new media texts' to were never the only forms of texts (see e.g. Elspaß 2005). Likewise, the 'new' forms often highlighted in computer-mediated communication analyses are not the only (and probably not even the most frequent) forms of texts in the new media, where a lot of 'traditional' communication is going on. However, as much as specific forms of text seem to be more salient in 'traditional' communication (and thus shaped our notion of text), other forms seem to be more salient in 'new' media, and the latter are usually those forms which seem to deviate from 'traditional' texts (cf. Squires 2010: 462-463). So it is maybe not so much (or at least not only) the media that change here, but mediality: the expectation that particular media consist of particular forms of communication, and that 'new' media should entail 'new' forms of communication (cf. Squires 2010: 462). Mediality expectations entail textuality expectations. The question, 'what is a text?', as discussed by Schmitz, implies the question of what social actors consider to be 'a text' (at a given time). Hence, from an interpretive point of view, the question is not so much whether text boundaries dissolve, but rather, whether textuality (and thus: mediality) expectations change. The same applies to 'efficiency'. Is efficiency really a communicative-historical constant, or is it rather a discursive construct that shapes the mediality expectations of particular ('econo-centric') societies?

What has been said for texts also applies to genres. How are genres conceived, delimitated, linked, ordered and evaluated by social actors themselves? Which mediality expectations do social actors have with regard to particular genres? Luginbühl suggests that the "unemotional, inverted pyramid style of the newsreader" is perceived as an "unmediated depiction of an absolute, unquestionable truth". However, to whom does this apply, and how do we know that? Furthermore: do social actors conceive the thing which is called 'super-genre' by Luginbühl as a coherent entity? Do they conceive what the author separates as 'genres' (e.g. an "opening credit”) as single entities? How do they relate the various parts of a TV news show in terms of weight, order, interrelations? In other words: do "genre profiles" exist outside the media linguist's head, and if so, do they look the same? If we perceive genres as functional social constructs and eth- 
no-categories (as Luginbühl does), what does this mean for genre profiles? These questions are clearly scratched in Luginbühl's chapter, but they are not answered (and probably cannot be answered easily). In any case, the mediality on the level of genre relations seems to be a challenging task for sociolinguistic media(tization) research.

This becomes most apparent in Squire and Iorio's chapter. This chapter deals with "reported" tweets, and it is clear that "reported" tweets are not the same as "tweeted" tweets. Since the authors did not (as far as I can see) compare the "reported" tweets with their "tweeted" counterparts (or even check if they really exist), their chapter actually cannot (and obviously also does not want to) make any statement about Twitter communication, but only about the representation of Twitter communication in newspapers (and furthermore, due to the method of corpus compilation, only about the subset which is explicitly framed by a particular verbum dicendi). Now, what characterizes reported tweets on the level of mediality? Most notably a mediality tension, or polymediality, if you like it more Bakhtinean. Reported tweets are entextualized entities which are part of an intergeneric relation that contrasts - via the "intertextual gap" (Briggs and Bauman 1992: 149) - the mediality expectations displayed towards the matrix and the embedded genre, i. e. towards news reports on the one hand and towards tweets on the other. With this idea in mind, we could pose further questions: is the observed trend towards standardization related to a change in mediality expectations? And if so, on which level? Do the expectations towards tweeting change, or the expectations towards reporting tweets, or both? In other words: do Squires and Iorio, to re-use Bolters and Grusins (1999: 19) terms, observe a decreasing hypermediality (i. e. medial salience) of Twitter quotes? And if so, why is that? Does it conform to a decreasing hypermediality of tweets? A decreasing perception (and/or construction) of the "genre gap" by the journalists? Or both? And if hypermediality decreases (and 'immediacy' therefore raises), what about the reported tweets that are not framed by a verbum dicendi and therefore not detectable by the authors' method? Isn't it important to include those in order to complete the picture of how tweets are "perceived" as a medium - to get hold of their mediality?

I do not know the answer to any of these questions. However it strikes me that the instructive thoughts about mediatization and sociolinguistic change provided by the three chapters in this section could be productively complemented by a sharper focus on the change of media perceptions and the question of how the change of these perceptions relates to the change of media and language use. 


\section{References}

Agha, Asif 2005: Voice, Footing, Enregisterment. Journal of Linguistic Anthropology 15/1: 38-59.

Androutsopoulos, Jannis 2006: Introduction: Sociolinguistics and computer-mediated communication. Journal of Sociolinguistics 10/4: 419-138.

Barnhurst, Kevin G. and John C. Nerone 2001: The Form of News. A History. New York/London: Guilford.

Bolter, Jay David and Richard Arthur Grusin 1999: Remediation. Understanding New Media. Cambridge, MA/London: MIT Press.

Briggs, Charles L. and Richard Bauman 1992: Genre, Intertextuality, and Social Power. Journal of Linguistic Anthropology 2/2: 131-172.

Bucher, Hans-Jürgen 1998: Vom Textdesign zum Hypertext. Gedruckte und elektronische Zeitungen als nicht-lineare Medien. In: Werner Holly and Bernd Ulrich Biere (eds.): Medien im Wandel. Opladen: Westdeutscher Verlag: 63-102.

Elspaß, Stephan 2005: Sprachgeschichte von unten. Untersuchungen zum geschriebenen Alltagsdeutsch im 19. Jahrhundert. Tübingen: Niemeyer.

Gershon, Ilana 2010: Breaking up is hard to do: Media switching and media ideologies. Journal of Linguistic Anthropology 20/2: 289-405.

Habscheid, Stephan 2000: 'Medium' in der Pragmatik. Eine kritische Bestandsaufnahme. Deutsche Sprache 28/2: 126-143.

Johnson, Sally and Astrid Ensslin 2007: Language in the Media: Theory and Practice. In: Sally Johnson and Astrid Ensslin (eds.): Language in the Media. Representations, Identities, Ideologies: 3-22. London: Continuum Press.

McGann, Jerome J. 1991: The Textual Condition. Princeton: Princeton University Press.

Mersch, Dieter 2009: Medientheorien zur Einführung. 2nd ed. Hamburg: Junius.

Schneider, Jan Georg 2006: Gibt es nichtmediale Kommunikation? Zeitschrift für Angewandte Linguistik 44: 71-90.

Schneider, Jan Georg 2008: Spielräume der Medialität. Linguistische Gegenstandskonstitution aus medientheoretischer und pragmatischer Perspektive. Berlin/New York: de Gruyter.

Spitzmüller, Jürgen 2013: Graphische Variation als soziale Praxis. Eine soziolinguistische Theorie skripturaler 'Sichtbarkeit'. Berlin/Boston: De Gruyter.

Squires, Lauren 2010: Enregistering internet language. Language in Society 39: 457-492. 